\title{
Memória da Psicologia
}

\section{ECLÉA BOSI}

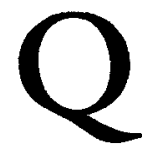

uando Lévi-Strauss recorda em Tristes trópicos os jovens de Sáo Paulo, evoca os nomes de seus encantadores disctpulos como flores de um fresco ramalhete; o primeiro nome evocado é Annita. Trata-se de Annita de Castilho e Marcondes Cabral, a criadora do curso de Psicologia.

Os primeiros psicólogos tiveram de ser autodidatas que abriam seu caminho antes do aparecimento das Faculdades. Era na Escola Normal que se estudava Psicologia: ali se formaram os primeiros laboratórios e por ela passaram Claparède, Henri Piéron, Helène Antipoff, Köhler e outros nomes ilustres, voltados em geral para o tema da Educaçáo. Dali surgiram os que impulsionaram a nascente Psicologia: Lourenço Filho, Noemi Silveira Rudolfer, Virginia Bicudo, Betty Katzenstein... Esta tradição vem sendo mantida pelos nossos pesquisadores da área de Psicologia do Escolar.

O engenheiro suíço Roberto Mange orientava, já em 1926, grupos de pioneiros na Psicologia Industrial.

Quando foi fundada nossa Faculdade, a Psicologia tornou-se matéria obrigatória nos três primeiros anos de Filosofia.

Entre 1935 e 1944, Jean Maugüé ensina Psicologia; aluno de Brunschvicg e Charles Blondel, suas aulas abordavam a percepção, a memória, a vida afetiva... Discutia com os alunos a teoria da Gestalt, a Psicanálise, a Fenomenologia. A partir de 45, chegou-nos Otto Klineberg, cuja orientaçáo, em suas grandes linhas, ainda hoje seguimos.

Nossa fundadora foi aluna dileta de Maugüé, Bastide, Lévi-Strauss e, nos Estados Unidos, de Koffka, Heider, Wertheimer, teóricos da Gestalt. Em 1953, ela propóe à Congregação da Faculdade a criaçáo do curso de Psicologia e, em 1957, inicia junto à sua Cadeira uma especializaçáo em Psicologia Clínica.

Estava criado o curso de Psicologia na saudosa Maria Antônia, onde fomos alunos de Filosofia com Cruz Costa, de Antropologia com Egon Schaden e Gioconda Mussolini, de Sociologia com Rui Coelho. 


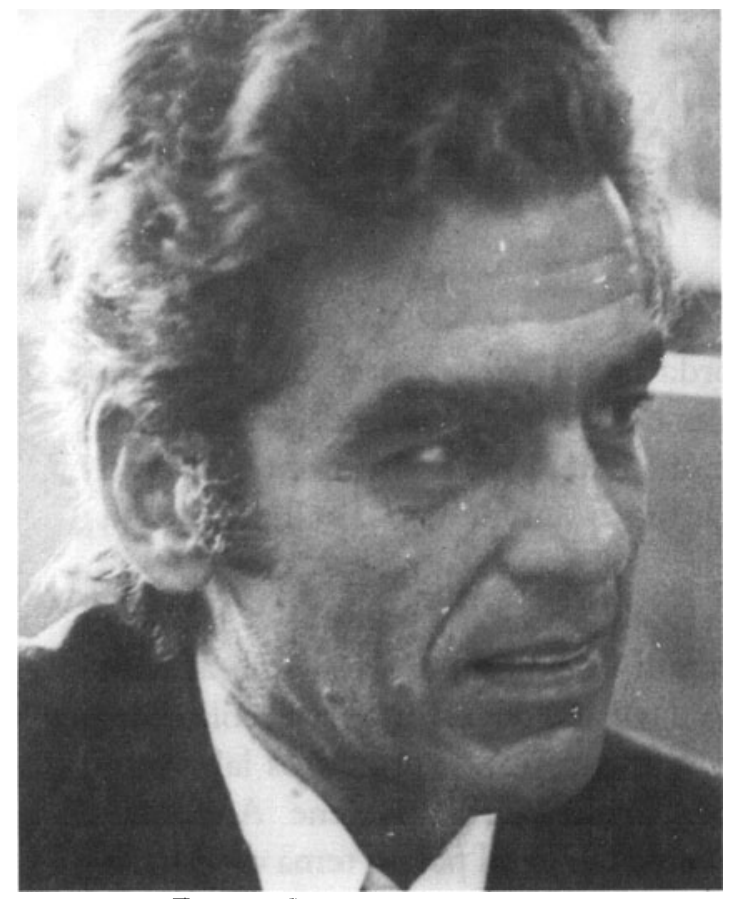

Dante Moreira Leite

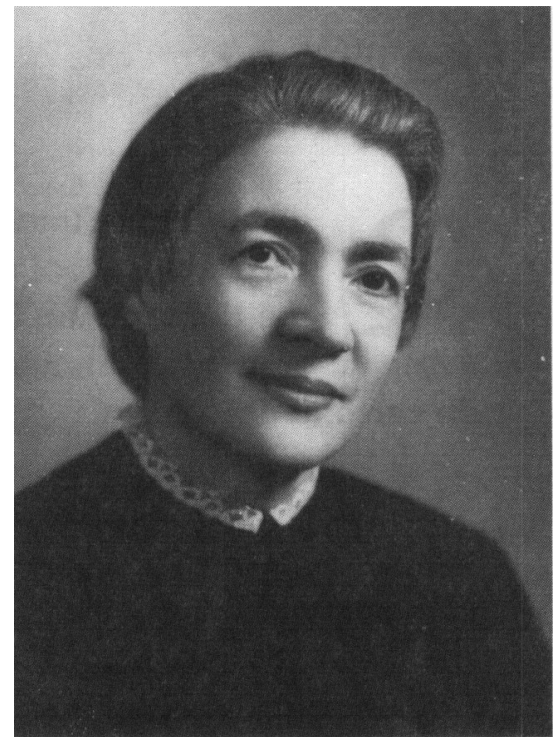

Annita Cabral

A Psicologia Experimental era dada por D. Annita em seu pequeno laboratório da alameda Glete. Alunos de outros cursos tentavam avançar sobre aquele espaço que cobiçavam. Ela nos ensinou, com picareta e enxada, a cavar no pátio uma trincheira para defendê-lo.

Tínhamos Psicologia Social numa casa simpática da rua Cristiano Viana, alguns vezes sentados na grama, à sombra das árvores do quintal. Desconhecíamos xerox ou apostilas; líamos na íntegra Adorno e Bergson, Heidegger e Scheler como primícias da ciência psicológica, já nos primeiros anos.

No Hospital Psiquiátrico de Vila Mariana, assistíamos às elegantes preleçōes do professor Cícero Christiano de Souza. Ouvíamos com assombro dizer que o professor Durval Marcondes se correspondera com Freud. E o sapiente mestre Anibal Silveira nos introduzia nos claroescuros do teste Rorschach.

A Psicologia Clínica estava sediada na rua Jaguaribe. Acresce que os estágios de Psicologia do trabalho eram feitos na Volkswagen, em São Bernardo, nas férias de julho, e lá íamos nós, em ônibus da fábrica que nos recolhia ainda à luz das estrelas. Não nos faltavam, pois, trajetos a percorrer nesse curso itinerante. 
Em 1961, chega dos Estados Unidos o professor Keller, que abriu novos rumos à Psicologia Experimental nela formando um grupo behaviorista que ficou sob a orientaçáo de D. Carolina Martuscelli Bori. Formou-se ali também com o professor Walter H. de Andrade Cunha uma linha independente de etólogos.

O Instituto de Psicologia começou a existir em 69: estava cortado o cordão umbilical com a Filosofia, ao menos espacialmente. Da rua Maria Antônia, mudamos para os precários barracōes à beira do rio, aqui na Cidade Universitária. Seu primeiro diretor foi o professor Arrigo Angelini.

D. Annita havia sido alijada por grupos fanáticos que repudiavam o lastro filosófico da Gestalt. Antes que sua entrada nas classes fosse barrada pela força, pude assistir ainda suas últimas aulas no apagar das luzes.

Nessa escura época da repressão política, a colega Iara Iavelberg partiu para a luta clandestina e, hoje, nosso Centro Acadêmico tem o seu nome. Foram anos de resistência e perseguição em que perdemos alunos queridos.

Hoje o Instituto tem quatro Departamentos:

- Psicologia Experimental;

- Psicologia Clínica;

- Psicologia da Aprendizagem, Desenvolvimento e Personalidade;

- Psicologia Social e do Trabalho.

$\mathrm{E}$ temos serviços de atendimento à comunidade quer na área terapêutica, quer na de orientação e seleção profissional.

Embora jovem, a Psicologia tem já sua memória e se honra de ter contado entre seus professores com Dante Moreira Leite, autor do livro $O$ caráter nacional brasileiro. Estudioso do preconceito $\mathrm{e}$ do etnocentrismo, foi superador de uma ideologia tenaz: a do caráter nacional. Em 1971, Dante repetiu com seus alunos no Laboratório de Psicologia Social a experiência famosa de Asch sobre o conformismo, na qual o sujeito nega o que seus olhos vêem, sob pressão do grupo. $\mathrm{Na}$ juventude contestadora da época, encontrou índice de obediência ao grupo, de submissáo à maioria, ainda mais alto que no experimento clássico. Se o resultado nos deixou boquiabertos, Dante náo ficou deprimido. Ensinou-nos que devemos voltar a atenção para quem não foi esmagado pela maioria, para o dissidente que procura solitário a liberdade de perceber num mundo adverso.

Estes foram e continuam sendo nossos mestres.

Ecléa Bosi é professora do Instituto de Psicologia da USP. 


\section{Linhas de pesquisa: Psicologia Social e do Trabalho}

\section{Cultura e memória social}

Esta linha está voltada para o estudo do registro e da interpretaçáo cultural do espaço e do tempo vividos pelo sujeito.

\section{Problemas bumanos no trabalbo}

Linha voltada para o estudo de relação homem-trabalho no contexto das organizaçôes e instituiçóes bem como no trabalho autônomo e voluntário.

Estudos teóricos-experimentais e de percepgáo de pessoa

Estudos teóricos-experimentais de situaçóes interpessoais, naturais ou construídas, sob o enfoque da percepção de pessoa. Incluem estudos fundamentados na teoria de Heider, sob o equilíbrio e a atribuição de causalidade.

\section{Estudos sobre a socializafáo e a aquisifáo da identidade}

Linha de pesquisa voltada para a compreensão da dinâmica do processo de socializaçáo primária com ênfase especial em suas conseqüências para a formação da identidade dos indivíduos.

\section{Formagáo de atitudes, palores e estruturafáo ideológica}

Esta linha de pesquisa procura mostrar os fatores psicológicos que influem na adoçáo de sistemas de valores e nas posiçóes ideológicas dos indivíduos.

\section{Epistemologia genética e psicologia social}

A Psicologia Social se ocupa especificamente do indivíduo inserido num sistema de relaçóes com os outros indivíduos, os objetos e a natureza epistemologia genética nos dá instrumento para explicar como são possíveis essas relações, isto $k$, os pressupostos que identificamos como condiçáo de toda interaçáo possível estamos estudando essas condiçóes.

\section{Indipiduo, grupo e sociedade}

Esta linha se ocupa sobretudo da ligaçáo indivíduo-sociedade através do estudo desses dois extremos de um continuum que implica questốes referentes aos níveis societários (grupos, instituiçóes e comunidade) e as classes sociais. 
Esta linha tem por finalidade desenvolver conhecimento sobre a problemática da difusão do conhecimento lato sensu através de propostas sobre problemas sociais específicos utilizando-se a metodologia de pesquisa - açáo e privilegiando-se estratégias participativas no processo de planejamento.

\section{Psicologia social da arte}

Esta linha de pesquisa ocupa-se do caráter psicossocial das manifestaçóes artísticas através da análise das questôes que essas manifestaçóes implicam no tocante ao campo de relaçóes formado pela experiência estética, isto é, pelos processos nela envolvidos (por exemplo, a percepção, o gosto, a imaginação etc.) pelos objetos estéticos correlatos (a obra de arte e, nesse caso, um objeto privilegiado) e pelo contexto sóciocultural em que se verificam.

Interafáo de fatores psicologicos, fisiológicos e sociais na dindmica sauide-enfermidade

Enfermidade e saúde são fenômenos bio-psico-sociais que exigem um estudo mais amplo, considerando o processo de interação do homem com o meio-ambiente físico e social. Essa linha de pesquisa empenha-se em investigar e integrar os fatores básicos-psíquicos, biológicos e sociais - presentes nesses fenômenos.

Imagindrio e fendmenos psico-sociais

Reflexão e pesquisa sobre as possíveis contribuiçóes da teoria junguiana para a teoria e pesquisa em Psicologia Social.

\section{Psicologia do esporte}

Esta linha tem por objetivo específico pesquisar e teorizar a contribuiçáo da psicologia social (e da teoria de stress motivação) na melhor compreensão dos eventos esportivos, na preparaçáo de atletas, na especificidade das modalidades, bem como na atuação de técnicos e juízes.

\section{Psiconeuroimunologia e processos sociais}

Esta linha de pesquisa concentra os projetos de pesquisa que estudem a relaçáo entre os processos sociais e psico-sociais com a psiconeuroimunologia. Este novo ramo da ciência objetiva integrar os conhecimentos da psicologia com os da neurologia e imunologia permitindo assim a criaçăo da verdadeira interdisciplinaridade. 


\section{Linhas de pesquisa: Psicologia Clínica}

\section{Diagnóstico psicológico}

- Imagem Corporal em grupos atípicos

- Masculinidade-Feminilidade no contexto do diagnóstico psicológica

- A prova do bestiário em crianças brasileiras

- Estudo da validade interna do Berufs Belder-Test de Achtinich I

- Aplicaçáo do teste estilocrômico em psicossomática

- O teste de Pfistel em crianças deficientes mentais

- O teste de Rorschach em drogadictos

- Características do desenho da figura humana e do teste de - apercepção temática de gestantes paulistanas: algumas implicaçóes para assistência pré-natal

- Investigação do Espaço Transicional através do procedimento de desenhos-estórias

- Com a palavra o cliente - uma escuta de vivência no processo psicodiagnóstico

- Avaliação psicológica de pacientes com Lupus E.S.

- Escala evolutiva da criança brasileira

- Estudo da validade do teste estilocrômico em psicopatologia

- Aspectos de conteúdo dos testes de apercepçáo temática em mulheres gestantes e não gestantes.

- Caracterização da população em atendimento psicoterápico individual no Ceipusp e caracterizaçáo de seu processo de diagnóstico

- Correlaçáo entre o exame psicomotor e as demais provas em psicodiagnóstico.

\section{Psicologia e psicoterapia dindmica}

- O surgimento do Eu através do processo psicanalítico segundo a teoria de Lacan

- Psicoterapia psicanalítica com drogadictos

- A consulta psicoterápica na clínica-escola

- Estudo de método para superar resistências narcísicas .

- Fantasia, sonho e pensamento do enquadre psicanalítico

- Investigaçáo epistemológica do campo do inconsciente freudiano

- Manifestação de percepções novas da realidade que a linguagem consciente esquizóide comunica em contraposição as percepçôes distorcidas reveladas pelos mecanismos esquizóides.

- Estudo da evoluçáo do padráo de sono em criança

- Motivaçáo para a escolha da funçáo do psicoterapeuta

- Estudo da validade do teste estilocrômico em psicopatologia

- Desenvolvimento do sono em crianças - aspectos afetivos 
- Clínica psicanalítica dos distúrbios psicomotores

- Psicoterapia individual com intervenção clínica sobre a família

- Aspectos da realidade psíquica náo sensorial: fantasia, amor, arte no campo psicanalítico

- Grupo de sonho com adultos: alcance do ponto de vista da dinâmica e evolução psíquicas no sujeito

- Gestação na adolescência: aspectos psicodinâmicos

- Desenvolvimento do tempo (ritmo) subjetivo

- Mitologia grega e psicanálise

\section{Psicologia prepentipa comunitária}

- Métodos e indicaçóes e limites da psicoterapia preventiva da família

- Conduta socialmente inadequada de jovens em comunidades fechadas

- Comprovação do modelo teórico de avaliação - intervenção mediante abordagem longitudinal

- A psicologia clínica na comunidade: subsídios para atuaçáo no âmbito de uma creche

- Especificação de características comportamentais de crianças encaminhadas a uma clínica escola de psicologia e verificaçáo de como diferem das crianças do mesmo sexo, idade e nível sócio econômico não encaminhadas.

- Desenvolvimento de um sistema de atendimento psicológico a comunidade como programa suplementar no curso de formaçáo psicólogos

- Diagnóstico institucional-comunitário

Psicologia do excepcional, psicomotricidade e distrirbios psiconeurológicos

- Psicodiagnóstico dos distúrbios específicos de aprendizagem

- O modelo neuropsicolingüístico do ITPA

- Organizaçáo neurológica no desenvolvimento em crianças hiperativas

- Características eletroencefalográficas na hiperatividade na infância

- Aspectos psicodinâmicos na gênese da hiperatividade em crianças, na idade escolar

- A dominância lateral em crianças: aspectos eletromiográficos

- A análise da importância relativa da hereditariedade e do ambiente na gênese e desenvolvimento da dominância lateral

- O conceito de lateralidade

- Uma avaliação do significado do conteúdo de estímulos verbais em crianças durante registro E.M.g. contínuo

- Alteraçóes hematológicas e tomográficas com convulsão recente 
- Aspectos lxicos e fonológicos na aprendizagem escolar da escrita e leitura em crianças

- Fatores psicológicos e neurológicos na patogênia da síndrome hipercinética em crianças na idade escolar

Modificafáo do comportamento e terapia comportamental

- Influência de algumas variáveis ecológicas sobre o comportamento infantil

- Sexualidade: funções e disfunçôes

- Anatomia da intervençáo clínica comportamental

Psicopatologia: assistencia e prepenfão

- Representaçóes de caminhoneiro sobre a doença mental

- Representaçōes de pacientes psiquiátricos internados sobre doença mental

- Representações de profissionais de saúde sobre deficiência física

- Representaçóes de endocrinologista sobre paciente obeso

- Representaçóes de homicidas sobre a doença mental

- Representaçóes de colegiais paulistanos sobre a doença mental

- Representaçóes de profissionais de TV sobre a doença mental

- Uso de técnicas psicodramáticas na psicoprofilaxia da drogadiçáo

- Delinqüiência e abandono

- Aspectos psicológicos da disputa da guarda

- Dupla exclusáo: o paciente psiquiátrico aidético

Atendimento psicológico em clínica escola

- Grupo de espera recreativo

\section{Linhas de pesquisa: Departamento de Psicologia Experimental}

\section{Problemas tedricos da psicologia}

- Natureza e história da psicologia como ciência - construção de teorias em Psicologia. Gênese histórica e conceitual da Psicologia e Psicanálise. Problemas epistemológicos e metodológicos da pesquisa em Psicologia.

- Análise do comportamento operante

- Problemas conceituais e metodológicos na análise experimental do comportamento. Análise e medida do comportamento verbal. Análise de contingências e comportamento em situaçáo de ensino, de autocontrole e de interação social. Análise de contingências ambientais. Esquemas de reforçamento. 
Estudo do sistemas visual animal e humano. Ênfase em mecanismos de codificação na retina da informação sobre cor, forma e movimento.

Técnicas eletrofisiológicas de registro e marcaçáo intracelular. Técnicas comportamentais de discriminação de cor e forma. Regulaçáo química do comportamento, ênfase em comportamento sexual, emocional e patológicos. Mecanismo de neurotransmissão. Efeito de drogas e dietas no comportamento.

\section{Comportamento animal}

Estudo naturalístico e experimental do comportamento das espécies animais em termos de causação, evolução e funçáo adaptativa. Procedimentos etológicos de categorizaçăo, descriçăo e análise do comportamento. Análise de sistemas motivacionais e dos efeitos da experiência individual. Flexibilidade e pré-programação na ontogênese do comportamento.

\section{Processos cognitivos, afetivos e sociais do ser humano}

O estudo da percepção através de relatos verbais e outros indicadores; métodos psicofísicos. Motivação e emoção. Aspectos motivacionais dos processos cognitivos. Estados subjetivos e consciência. Movimentos expressivos: percepçáo, comportamento $e$ aspectos interativos. Interdependência do comportamento em grupos de trabalho. Relação de conflito entre grupos sociais: minorias ativas. Cogniçáo social: o estudo de representaçáo. Desenvolvimento do comportamento social na criança - enfoque etológico: interação criança/criança, formação, de relaçốes sociais, descrição e análise de estrutura de grupos sociais. Comunicação verbal e habilidades sociais.

\section{Curso de pós-graduação em Psicologia Escolar}

Neste curso foram desenvolvidas as seguintes linhas de pesquisa:

- Desempenho escolar: aspectos psicológicos, culturais e institucionais;

- Aprendizagem e desenvolvimento cognitivo;

- Meios de comunicaçăo de massa, tecnologia educacional e os processos de aprendizagem e de desenvolvimento humanos;

- Relaçóes interpessoais, aprendizagem permañente e desenvolvimento pessoal;

- Atividades lúdicas e desenvolvimento humano;

- Elaboraçáo e emprego de técnicas de exame psicológico. 
Atualmente, em funçáo da renovação dos quadros de docentes e das orientaçóes de pesquisa que têm abordado temas ligados às perspectivas interdisciplinares no estudo das relaçōes entre a Psicologia e a Educação, está havendo uma ampla reformulaçáo dessas linhas de pesquisa. 